\title{
PROCESSO HISTÓRICO DE FORMAÇÃO DA JUSTIÇA DO TRABALHO NO BRASIL: DO CONSELHO NACIONAL DO TRABALHO AO TRIBUNAL SUPERIOR DO TRABALHO
}

\section{HISTORIC PROCESS OF CREATION OF LABOR JUSTICE IN BRAZIL: FROM NATIONAL LABOUR COUNCIL UNTIL SUPERIOR LABOUR COURT}

RAFAEL LAMERA GIESTA CABRAL

Doutor em Direito, Estado e Constituição pela Universidade de Brasília - UnB (2016). Mestre em Ciência Política pela Universidade Federal de São Carlos - UFSCar (2010). Atualmente, é professor adjunto no curso de Direito e Coordenador do Programa de Pós-Graduação Stricto Sensu em Direito (Mestrado Acadêmico) e docente no Programa de Pós-Graduação em Administração Pública (PROFIAP Mestrado Profissional) da Universidade Federal Rural do Semi-Árido (UFERSA). É Editor-chefe da Revista Jurídica da Universidade Federal Rural do Semi-árido - REJUR. Desenvolve pesquisas no campo da História do Direito, com ênfase na história constitucional e direitos sociais entre as décadas de 1920 e 1940. Pesquisa também na área de Administração Pública com foco na gestão democrática nos Conselhos Municipais e Gestão de Risco Institucional.

EDDLA KARINA GOMES PEREIRA Doutora em Desenvolvimento e Meio Ambiente (UFPB - 2016). Mestra em Ciências Jurídicas (UFPB - 2010). Possui máster em Gênero e Políticas de Igualdade(Universidad de Valencia/Espanha - 2009). É especialista em Direito Processual (UNISUL - 2009). Atualmente é professora Adjunta 1 da Universidade Federal da Paraíba - UFPB, bem como ensina em cursos de especialização nas áreas de Processo Civil, Direito do Trabalho e Direito Administrativo e Gestão Pública. Concentra linhas de pesquisa na área de Processo e Direito do Trabalho, Direitos Humanos, Direito Ambiental, Desenvolvimento Rural e Economia Solidária. 


\section{VITÓRIA VIRNA GIRÃO CHAVES}

Membro de Pesquisa em Direito pela Universidade Federal Rural do SemiÁrido(2017). Atualmente é da Universidade Federal do Ceará. Tem experiência na área de Direito.

\section{RESUMO}

A evolução da legislação trabalhista e previdenciária brasileira, desde a Primeira República até 1930, pode ser compreendida a partir da história de suas instituições. Trabalho e previdência social estão inseridas em um contexto de mudanças complexas que incorporaram mecanismos administrativos e judicantes para efetivaras leis até então elaboradas. Como primeira instituição, surge, em 1923, o Conselho Nacional do Trabalho (CNT), órgão inicialmente consultivo, cujas funções ampliaramse até assumir um caráter jurídico, sendo transformado em Tribunal Superior do Trabalho (TST). Neste artigo, busca-se, através de pesquisa bibliográfica e documental, analisar os principais pontos dessa transformação, partindo de uma perspectiva histórica e da hipótese de que essa transição trouxe forte influência para a compreensão social da Justiça do Trabalho. Observa-se que o CNT foi essencial para criar procedimentos e argumentos que são utilizados no âmbito da Justiça do Trabalho, possuindo uma contribuição histórica significativa para a ampliação e fortalecimento do Direito do Trabalho.

PALAVRAS-CHAVE: Conselho Nacional do Trabalho; Justiça do Trabalho; Tribunal Superior do Trabalho.

\section{ABSTRACT}

The evolution of the Brazilian labor and social security legislation - from the First Republic until 1930 -can be understood from the history of its institutions. Work and social security are embedded in a context of complex changes that incorporatedmanagerial and judicial mechanisms to implement the laws that have been elaborated. In this context, the National Labor Council (CNT) was created in 
1923, an initial advisory body, whose functions were extended to a legal status and transformed into a Superior Labor Court (TST). In this article, we aim to analyze through bibliographical and documentary research - the main points of this transformation, starting from a historical perspective and the hypothesis that this transition brought a strong influence on the social understanding of Labor Justice. It was noted that the CNT was essential to create procedures and arguments that are used in the scope of Labor Justice. The CNT also had a significant historical contribution to the expansion and strengthening of Labor Law.

KEYWORDS: National Labor Council; The Labor Court; Superior Labor Court.

\section{INTRODUÇÃO}

O Direito do Trabalho é uma vertente jurídica que assume um caráter preponderantemente humanitário, visto que, diante de uma relação economicamente desfavorável para o empregado, objetiva conferir uma maior proteção aos trabalhadores, sobretudo em contextos de vulnerabilidade. Trata-se, ademais, de um direito deveras dinâmico, de presença real e constante nas diversas sociedades, e um importante instrumento não somente de crescimento econômico, mas também de promoção de um desenvolvimento que se converta em bem-estar humano.

A Justiça do Trabalho no Brasil, órgão que dá voz aos direitos trabalhistas, é responsável por apresentar as soluções jurídicas necessárias para fortalecer e garantir a aplicação do Direito do Trabalho. Por esse motivo, conhecer o seu processo de formação histórica é essencial para compreender os seus fundamentos e a sua importância, principalmente no cenário atual do país, no qual em nome da "modernização"das relações de trabalho, há substanciais ofensas à dignidade dos trabalhadores.

A história da Justiça do Trabalho no Brasil, como qualquer processo de formação institucional, não é marcada por um surgimento progressivo, linear e repentino. A sua construção, em meio às influências das mudanças sociais, políticas 
e econômicas, perpassa por movimentos pendulares de avanços e retrocessos, tal como ocorre com o próprio processo histórico de constituição do Direito do Trabalho.

O debate acerca da construção dos direitos sociais no Brasil, especificamente dos direitos trabalhistas, remonta inevitavelmente ao período de intensa criação legislativa na década de 1930, sob o comando do Governo Vargas. A profícua regulamentação da legislação trabalhista no período, não significa, porém, como se costuma acreditar, que os direitos trabalhistas surgiram de maneira súbita e completa, englobando de uma única vez toda a legislação do trabalho que conhecemos hoje, e, menos ainda, que os conflitos trabalhistas eram tratados e compreendidos da mesma forma como são atualmente.

A questão social no Brasil, pois, não é fruto na década de 1930, visto que as primeiras manifestações decorrentes dos problemas sociais relacionados ao trabalho são bem mais remotas, e se referem aos movimentos grevistas, organizações sindicais, e inclusive com ensaios de legislação trabalhista na transição dos séculos XIX para XX (FAUSTO, 2006).

No contexto internacional, a criação da Organização Internacional do Trabalho (OIT), por meio da Conferência da Paz, em 1919, foi um marco decisivo para a afirmação da dignidade humana e da necessidade de proteção dos trabalhadores (BIAVASCHI, 2011, p.88).

Em 1918, houve a criação da Comissão de Legislação Social na Câmara dos Deputados e, em 1919, a aprovação da primeira lei sobre acidentes de trabalho do Brasil. Em 1923, houve a sanção da Lei Eloy Chaves, criando as Caixas de Aposentadoria e Pensão (CAPs) para os funcionários das empresas de ferro brasileiras, forma primária de previdência social (BIAVASCHI, 2011, p.92; GOMES, 1979).

Os avanços na regulamentação do trabalho consequentemente favoreceram mudanças na forma como eram tratados e solucionados os conflitos trabalhistas. Com a regulamentação crescente do direito do trabalho, especialmente a partir da década de 1910-20, surgiu a necessidade da criação de um órgão administrativo que desse amparo aos direitos recém-criados, principalmente relacionado à supervisão das CAPs. 
Ademais, objetivava-se realizar os compromissos internacionais assumidos por meio do Tratado de Versalhes, que deu origem à OIT, regulamentando minimamente, inclusive em nível constitucional, garantias essenciais à dignidade no meio ambiente do trabalho no Brasil. Foi nesse contexto que, em 1923, criou-se o Conselho Nacional do Trabalho (CNT), vinculado ao Ministério da Agricultura, Indústria e Comércio, com atribuições consultivas, orientando os poderes públicos em assuntos que envolviam a organização do trabalho e da previdência social, além de exercer funções fiscalizadoras e administrativas (BRASIL, 1923).

A complexidade nas relações de trabalho, a intensificação dos conflitos e o surgimento de novas necessidades decorrentes da dinâmica do mercado proporcionaram o acúmulo e a ampliação de atribuições do CNT, que de órgão meramente consultivo passou a ter função jurídica (SOUZA, 2007).

Com a progressiva ampliação de atribuições do CNT e a complexidade dos conflitos trabalhistas e, reflexamente, da legislação, tornava-se inevitável a necessidade de que a função de dirimir os conflitos deixasse a esfera administrativa e passasse a ter um caráter mais jurídico. Assim, ao longo dos pouco mais de 20 anos de funcionamento, o CNT produziu em torno de 50 mil decisões, envolvendo acórdãos e decisões monocráticas (CABRAL, 2015, p.16).

O processo de institucionalização da Justiça do Trabalho se iniciou com a Constituição de 1934, que the conferiu, em seu artigo 122, a função de "dirimir questões entre empregadores e empregados" (BRASIL, 1934). Mantida na Constituição de 1937, a institucionalização da Justiça do Trabalho assumiu novos contornos e, em 1939, por meio do Decreto-Lei n 1.237, o CNT passou a ser "tribunal superior da Justiça do Trabalho" (BRASIL, 1939), ainda que o funcionamento da Justiça do Trabalho somente tenha ocorrido em 1941.

A transformação do CNT em Tribunal Superior do Trabalho, no entanto, só ocorreu propriamente por meio do Decreto-lei no 9.797, em 1946, embora a Justiça do Trabalho somente tenha passado ao âmbito do judiciário com a promulgação da Constituição de 1946, quando o CNT deixou de estar vinculado ao Executivo federal (BRASIL, 1946).

O objetivo desta investigação é trazer à tona a formação institucional das estruturas que viabilizaram a Justiça do Trabalho enquanto instituição, a partir do CNT 
até sua transformação em TST. Para que o objetivo fosse alcançado, lançou-se mão de um aparato metodológico que mesclou o procedimento técnico bibliográfico, elaborado a partir de materiais anteriormente publicados, baseado em dados qualitativos, com uma coleta documental de informações no Fundo de Arquivo CNT, hospedado no núcleo de Gestão Documental e Memória do TST, visando analisar importantes documentos que são subsídios para a breve análise histórica realizada sobre a transformação do CNT em TST. Por fim, há uma análise sistemática da hipótese estudada, tendo em vista que se considera a constante interação social, política e jurídica do objeto deste artigo.

No que diz respeito à organização estrutural, inicialmente se busca compreender como se deu o processo de formação do CNT e qual o papel de cada setor social na questão trabalhista. Em seguida, trata-se do surgimento e da evolução do CNT no legislativo, especificamente. Por fim, analisa-se o processo de transformação do CNT em TST, delimitando-se a sua função propriamente jurídica.

Nesta oportunidade, far-se-á uma breve apresentação da evolução do tratamento dado às causas trabalhistas no intervalo de 1923, com a criação do CNT, até 1946, quando houve a sua conversão em Tribunal Superior do Trabalho, observando-se os caminhos traçados para a resolução de conflitos trabalhista no Brasil, como também para a aplicação e o fortalecimento da legislação trabalhista vigente à época.

\section{AS EXPERIÊNCIAS DE REGULAÇÃO TRABALHISTA}

O estudo acerca do surgimento da legislação trabalhista e previdenciária no Brasil é formado por diversas perspectivas: umas que percebem a presença de uma postura ativa dos trabalhadores - que reivindicaram direitos em meio a um ambiente laboral exaustivo, perigoso e insalubre e outras que identificam uma inércia da classe, notadamente até 1917, diante de uma atuação do Estado que intercala períodos de concessões e repressão ao movimento operário, a depender do cenário político e econômico vigente, no contexto nacional e internacional (BARBOSA, 2009). 
A interpretação e o estudo do processo de construção das leis trabalhistas e previdenciárias, sobremaneira a partir da década de 30 , indicam que a percepção controversa da doutrina sobre o processo de estruturação destes direitos sociais no país se aliava, pelo menos até a década de 70 , a essa última tendência interpretativa: tanto relatos científicos que retratavam o senso comum, como trabalhos históricos evidenciavam uma inércia obreira diante de períodos de avanços e retrocessos no reconhecimento público de direitos laborais e previdenciários (UNTURA NETO, 2013, p.16).

Essa noção costumava posicionar a regulamentação das relações trabalhistas como uma "outorga" de garantias feita por um Estado que segue um cenário internacional de intervenção nas relações laborais, via ampliação de direitos sociais. Essa perspectiva reforça, ainda, a ideia de uma inércia - ou pelo menos de uma falta de organização coletiva estruturada - por parte dos trabalhadores, que foram facilmente "domesticados" pela legislação e pelo sistema sindical, relegando ao trabalhador a posição de mero espectador das inúmeras mudanças ocorridas (SOUZA, 2013, p.11-13).

A partir de novas pesquisas na década de 1970, passaram a analisar os movimentos históricos de atuação dos trabalhadores na busca e conquista de reconhecimento como meio de compreender a formação histórica da legislação laboral e previdenciária do país, pois os operários foram muito mais persuadidos politicamente do que forças políticas vivas no processo na formação normativa social brasileira.

A ideologia predominante na oposição considerava que a regulamentação do trabalho na época sequer ponderava a existência de uma questão social no Brasil, encarando a legislação como uma forma de "precipitar" tais problemas (SOUZA, 2013, p.26-32).

A mudança na percepção sobre a invenção pública no Direito do Trabalho, porém, passou a considerar pontos que fogem dessa relação mando-obediência, considerando muito mais complexa a relação entre trabalhador, Estado e burguesia, conforme afirma Samuel Fernando de Souza: 


\begin{abstract}
A ruptura com a crença em um Estado que centralizava o controle da sociedade possibilitou a emergência de estudos que tratavam os trabalhadores como agentes capazes de estabelecer relações ativas com as instituições. Ângela de Castro Gomes observou na relação entre Estado e trabalhadores, ao longo da invenção do trabalhismo, a construção de um "pacto" que não anulava a experiência dos beneficiários do direito social e que tornava muito mais complexa a "troca de benefícios" por "obediência política". Em torno da noção de "pacto" entre trabalhadores e Estado, Jorge Ferreira abordou a estratégia dos trabalhadores para obtenção de benefícios a partir da apropriação dos discursos políticos e uso de estratégias discursivas para solicitar benefícios (SOUZA, 2007, p.16).
\end{abstract}

Assim, a partir dessa perspectiva, verifica-se que a regulamentação das relações de trabalho no Brasil teve influência inevitável dos movimentos operários que começaram a se organizar propriamente ainda na Primeira República, os quais inicialmente sofreram violenta repressão por parte do Estado e alcançaram algum respaldo público muito mais por pressão política internacional e pela barganha de apoio político por formalização de direitos, do que por uma preocupação com as questões sociais da classe obreira (FAUSTO, 2006).

No decorrer da Primeira República, a estrutura social do Brasil sofreu uma notável diversificação, sobremaneira em decorrência da expansão da pequena propriedade produtiva no campo, decorrente da política do colonato ${ }^{1}$ entre imigrantes e cafeicultores, a expansão da classe média urbana e o surgimento da classe operária (FAUSTO, 1995, p.295). Contudo, dado que a principal atividade econômica estava vinculada ao setor primário e a indústria ainda figurava como inexpressiva do ponto de vista da economia nacional, a classe trabalhadora não era politicamente relevante e coletivamente organizada, o que fez com grande parte dos movimentos sociais não alcançasse êxito, possuindo alguma significância apenas quando envolviam setores agroexportadores, como ferroviários e portuários (FAUSTO, 1995, p.297).

O operariado em si estava pouco propenso à organização - também pela lógica produtiva rural não favorecer à coalizão - e possuía particularidades que dificultavam a unificação entre os vários centros industriais, de modo que não há que

1 O colonato foi uma estratégia utilizada pelos grandes proprietários de terra, que plantavam basicamente café, diante da abolição da escravidão e do incentivo a mão-de-obra imigrante, como forma de reorganizar a estruturação das relações de trabalho. Nessa relação, o colono recebia moradia e uma pequena parcela de terra, onde poderia cultivar gêneros alimentícios, enquanto se responsabilizava pela plantação e pelo cuidado dos cafezais. (FAUSTO, 1995, p.282-283). 
se falar propriamente em movimento operário anterior a 1917 (FAUSTO, 2006, p.163164).

Entre o final do século XIX e o início do século XX, as greves, em sua maioria, obtinham direitos pressionando os patrões, mas como tais benefícios não eram previstos legalmente, logo se perdiam no tempo e no espaço (FAUSTO, 1995, p.299).

O proletariado brasileiro, formado em sua maioria por trabalhadores "livres" e imigrantes, diferenciava-se na capital - Rio de Janeiro - e em São Paulo. Naquela, as reivindicações imediatas eram principais, como aumento de salários, limitação da jornada de trabalho e o reconhecimento dos sindicatos pelos patrões.

Em São Paulo, diante as influências das ideias do anarcossindicalismo², pleiteava-se a própria reconfiguração da organização social, via movimento coletivo de trabalhadores. Essas diferenciações decorriam da estrutura econômica e social das cidades - a capital era socialmente mais diversificada e possuía uma "classe média" de profissionais liberais e militares que facilitou uma política de colaboração de classes (FAUSTO, 2006, p.297-299).

A situação do operariado brasileiro só passou a interessar ao Estado e à burguesia e integrar com mais força as pautas políticas a partir da onda de greves entre 1917 e 1920 (FAUSTO, 2006, p.175-184). Antes mesmo de tais movimentos já havia alguma agitação em busca de reformas sociais, por exemplo, em 1903, até existiam regras de sindicalização que se dirigiam aos colonatos (BIAVASCCHI, 2011, p.91-92). ${ }^{3}$

No entanto, essas movimentações eram reduzidas e tinham importância pontual, visto que, até aquele momento, as preocupações principais eram voltadas para a população do campo, dado que o país era essencialmente rural. Em 1915, Maurício de Lacerda propôs a criação do Departamento Nacional do Trabalho, órgão

\footnotetext{
$2 \mathrm{O}$ anarcossindicalismo, bastante influenciado pelo sindicalismo francês, admitiam que a luta do movimento operário deveria ser orientada pela luta econômica, mais do que pela luta política. Defendiam que os sindicatos possuíam duas finalidades, as quais melhorar a condição de vida do trabalhador e formar a base organizacional econômica da sociedade após a abolição do Estado (FAUSTO, 2006, p.161).

${ }^{3}$ Registra-se o apontamento de Gomes e Silva (2013, p. 14), que desde 1905, Evaristo de Moraes, em seu Apontamento de direito operário, se referiu à necessidade de "organização oficial de um tribunal composto de patrões e operários, destinado a resolver as questões suscitadas a propósito do trabalho assalariado".
} 
que apesar de nunca funcionar verdadeiramente, foi importante para a posterior constituição do Conselho Nacional do Trabalho (CNT) (FAUSTO, 2006, p.183).

Pode-se dizer que foi pela atuação dos chamados "sindicatos amarelos" ${ }^{4}$, dos partidos políticos e de representantes das causas sociais, como Marcelo Lacerda e Nicanor Nascimento ${ }^{5}$, que o movimento operário passou a atuar dentro da máquina pública, recorrendo ao caminho da normatização como forma de conquistar os seus direitos, até mesmo diante da forte resistência de setores mais conservadores, como os industriais (FAUSTO, 2006, p.175-184).

A forma como os trabalhadores interagiram como essa estrutura burocrática e jurídica chama a atenção por ser inovadora. Na obra de Maria Pia Guerra (2015), é possível registrar que o movimento de conquista de direitos foi fruto de intensos conflitos sociais entre trabalhadores e empregadores, bem como com o Estado.

Em visita aos movimentos trabalhistas do final da década de 1910, Guerra se deparou com relatos de jornais produzidos por trabalhadores e processos judiciais, que apontavam que as repressões às greves ocorreriam de forma violadora às prerrogativas da Constituição de 1891 e ao entendimento do Supremo Tribunal Federal, que confirmava que trabalhadores estrangeiros residentes no país não poderiam ser expulsos, por mais perigosos e anarquistas que fossem. Muitos casos de expulsão foram divulgados pela impressa e levados ao Poder Judiciário.

Esses conflitos travaram longas disputas sobre os sentidos da Constituição e dos direitos ali observados. Como aponta Guerra (2015), de um lado estava o governo, criando fundamentos constitucionais para a sua atuação extra-legal e de outro, grupos anarquistas, formulando interpretações constitucionais para a ampliação de seus direitos.

\footnotetext{
4 Os "sindicatos amarelos" eram assim chamados por manterem boas relações com o Governo e a Polícia, admitindo a luta institucional. Foram representativos tanto em termos numéricos como em conquistas (FAUSTO, 2006, p.189).

${ }^{5}$ Nicanor Nascimento entrou na Câmara dos Deputados em 1911, para representar o primeiro distrito da Capital Federale Marcelo Lacerda, advogado de família de bases rurais de Vassouras, no Rio de Janeiro, foi eleito em 1912. O primeiro, durante sua atuação na Câmara, propôs inúmeros projetos de legislação trabalhista e trabalhou em defesa dos operários. Os dois aproximaram-se do movimento operário após as greves de 1917. Lacerda se considerava uma figura de transição, representando os interesses das classes operárias, enquanto não fossem eleitos deputados dessa classe (FAUSTO, 2006, p.181-183).
} 
O contexto de conflito também marcou iniciativas legislativas, como a observada em 1918, quando houve a criação de uma Comissão de Legislação Social na Câmara dos Deputados, da qual originou-se diversos projetos de leis e o projeto de um Código do Trabalho, do qual restou apenas a primeira lei sobre acidentes de trabalho, aprovada em 1919 (BIAVASCHI, 2011, p.92).

Em 1923, foi sancionada a Lei Eloy Chaves, criando as Caixas de Aposentadoria e Pensão, destinada a promover estabilidade aos empregados de estradas de ferro, como forma primária de uma espécie de seguridade social (FAUSTO, 2006, p.184). Houve, ainda, a aprovação de lei que regulamentou o regime de férias dos comerciários, em 1925; a proibição do trabalho aos menores de 12 anos e aos menores de 18 anos em trabalhos noturnos e em mineração com o Código de Menores, em 1927; dentre outras diversas legislações específicas.

Com a regulamentação crescente das relações trabalhistas, a forma como os conflitos eram tratados sofreu mudanças significativas. Tais disputas, que antes integravam o âmbito do direito civil, visto que o contrato de trabalho era considerado como contrato de locação de mão-de-obra (BIAVASCHI, 2011, p.92), passaram a requerer resoluções mais específicas, inclusive por um ramo especializado,de um órgão vinculado ao judiciário.

\section{O CONSELHO NACIONAL DO TRABALHO: CONSIDERAÇÕES SOBRE AS ENTRELINHAS DO SEU PROCESSO DE CONSTITUIÇÃO}

Com as variadas iniciativas de normatização trabalhista no Brasil tornou-se premente a necessidade de instauração de um órgão responsável para promover a regulação no campo trabalhista e previdenciários. Ademais, era imperioso realizar os compromissos internacionais assumidos pelo país após a criação da OIT, bem como, fiscalizar as Caixas de Aposentadoria e Pensão dos ferroviários, criadas a partir da Lei Eloy Chaves, ponto chave para a compreensão da experiência sobre direito previdenciário no Brasil.

A concepção de um órgão com tais atribuições se deu em 1923, com a criação do Conselho Nacional do Trabalho (CNT), por meio do Decreto $\mathrm{n}^{0} 16.027$, vinculado 
ao Executivo federal e instituído com a finalidade de ser "o orgão consultivo dos poderes publicos em assumptos referentes á organização do trabalho e da previdencia social" (BRASIL, 1923). Observe-se que a função inicial do conselho seria de fiscalização e não necessariamente a atribuição de dirimir conflitos entre empregados e empregadores.

As possíveis narrativas sobre a criação do CNT podem refletir inúmeros enredos. A criação de um órgão com a finalidade de organizar o trabalho e a previdência social pode assumir outras características, principalmente quando 0 contexto em que foi forjado nos remete a movimentos contraditórios. A referência que se levanta é a forma como a questão social era reconhecida no país. Desde as últimas grandes greves gerais no final da década de 1910, a questão social passou a ser um dos pontos das plataformas dos candidatos à presidência da República. Nesse resgate, Ângela de Castro Gomes e Fernando Teixeira da Silva (2013), registram que:

\begin{abstract}
Rui Barbosa, em 1919, concorrendo com Epitácio Pessoa como um verdadeiro anticandidato, inaugurou essa prática e sensibilizou muitos eleitores, inclusive ao se referir ao personagem-símbolo das misérias do povo brasileiro, recém-criado por Monteiro Lobato, o Jeca Tatu. O programa oficial lido por Washington Luiz em dezembro de 1925, quando do lançamento de sua candidatura, também mencionava a questão social, embora procurasse demonstrar que as causas ou os agentes das reivindicações não provinham da sociedade brasileira. Se a questão social existia, não era colocada como uma questão socioeconômica, e sim como um problema de natureza moral e sanitária, que dizia respeito ao bem-estar da família do trabalhador. (GOMES e SILVA, 2013, p. 18).
\end{abstract}

Nesse contexto, a lei de 1923, que além de reconhecer ao CNT a função consultiva para o Poder Executivo, também o colocava como responsável por estudar assuntos referentes à organização do trabalho e da previdência, tais quais a jornada de trabalho, sistemas de remuneração, contratos coletivos, métodos empregados de conciliação e arbitragem, trabalho de mulheres e menores, acidentes de trabalho, seguro social, dentre outros diversos assuntos.

Os estudos produzidos pelos conselheiros do CNT, quando aprovados por seus representantes, eram encaminhados ao governo, para posterior apresentação 
ao Congresso Nacional. Parte desses estudos podem ser resgatados a partir de suas publicações nas revistas institucionais do Conselho Nacional do Trabalho. ${ }^{6}$

O CNT acumulava, ainda, outras funções, como a fiscalizadora e administrativa, conforme pontua o artigo $8^{\circ}$ do Decreto $n^{0} 16.027$, ao estabelecer as competências da secretaria do órgão:

a) colligir e systematizar a documentação sobre os diversos problemas de nossa economia social; b)realizar inqueritos sociaes, ouvindo os profissionaes e interessados; c)promover a observancia do disposto nas leis numeros 1.150, de 5 de janeiro de 1904, e 1.907, de 29 de dezembro de 1906; d)propagar e fiscalizar a applicação das leis ns. 976, de 6 de janeiro de 1903, e 1.637, de 5 de janeiro de 1907; e)superintender a fiscalização de seguros contra accidentes do trabalho e quaesquer outros seguros operarios; f)superintender a fiscalização das caixas de pensões e aposentadorias de ferroviarios; g)executar quaesquer outros trabalhos referentes á organização do trabalho e da previdencia social. (BRASIL, 1923).

O CNT assumiu a função, ainda, de acompanhar o cumprimento do regulamento de execução da lei que previa a transformação do Serviço de Povoamento em Departamento Nacional do Trabalho, o qual geraria a criação de um Conselho do Trabalho responsável por estudar os assuntos e solucionar questões que o Departamento não conseguisse realizar de pronto (OLIVEIRA, 1988, p.269).

Ao longo da década de 1920, o CNT teve a sua competência ampliada de maneira significativa. Essa multiplicação de funções é decorrência da pressão dos trabalhadores para garantir que os direitos adquiridos fossem efetivados, diante da resistência dos patrões, tanto em relação à aplicação das normas relativas ao trabalho já existentes, quanto no desestímulo à criação de leis mais extensas.

Em relatório apresentado ao Presidente da República no ano de 1923, o Ministro da Agricultura destaca o crescimento de funções na secretaria do CNT devido à constante procura por trabalhadores nacionais e estrangeiros em busca da resolução de conflitos decorrentes das relações laborais. Diante do contexto, decidiuse cancelar o recebimento de tais demandas, com o intuito de conservar a atribuição consultiva do órgão (SOUZA, 2007, p.35).

\footnotetext{
${ }^{6}$ As revistas foram analisadas sistematicamente de 1925 (primeira edição) até 1932, quando foi descontinuada. A partir de 1941, com a instituição da Justiça do Trabalho, a revista foi retomada. Os exemplares estão disponíveis para consulta na biblioteca do Tribunal Superior do Trabalho.
} 
Como indicam Gomes e Silva (2013, p. 18), "entre os anos de 1927 e 1929, a mobilização política dos trabalhadores como legítimos participantes do processo eleitoral marcou algumas campanhas, sobretudo com a formação do Bloco Operário, que reivindicava leis sociais e denunciava seu descumprimento e a falta de fiscalização, com orientação do Partido Comunista Brasileiro". Em 1928, o Conselho Nacional do Trabalho passou por sua grande reforma institucional, com a criação de uma estrutura que passou a dirimir conflitos trabalhistas.

O inevitável crescimento da legislação trabalhista e previdenciária para algumas classes, especialmente os ferroviários e portuários (dada a maior organização coletiva destas categorias profissionais), ainda que gradual, foi incisivo nesse processo. Os conflitos levados ao CNT na época, em sua maioria, se referiam a problemas com a criação das Caixas de Aposentadoria e Pensão (CAP), à lei dos acidentes de trabalho e à aplicação da lei de férias (SOUZA, 2007, p.39-40).

Conforme deixa claro Moacyr Velloso Cardoso de Oliveira (1988), ao transcrever os relatos de Alfredo João Louzada:

Pondo de lado os problemas mais interessantes que lhe cabia estudar e cuidar, em virtude mesmo da falta de recursos com que lutava, o novo instituto [o CNT] passou a tratar das questões referentes às caixas de aposentadoria e pensões, a tal ponto que se tornou uma repartição inteiramente voltada aos assuntos dessas instituições de previdência. [...] (OLIVEIRA, 1988, p.270).

A responsabilidade pela fiscalização do cumprimento das leis criadas no período levou, inevitavelmente, o CNT a intermediar os conflitos entre patrões e empregados e se afastar do caráter meramente consultivo para o qual tivera sido instituído, consoante ao que afirma Souza (2007):

Conforme apontado por Morais Filho, o vínculo entre a Lei Eloy Chaves e o CNT garantiram uma atividade de avaliação e julgamento das demissões que em muito se assemelham aos litígios da nascente Justiça do Trabalho na década seguinte. Até o final dos anos 1920, as decisões do conselho haviam firmado longa jurisprudência pautada em recursos contra as decisões das CAPs, contra demissões feitas sem a observação do princípio da estabilidade dos trabalhadores (particularmente ferroviários) com mais de dez anos de trabalho e especialmente, de reclamações decorrentes do não cumprimento da lei de férias. [...] (SOUZA, 2007, p.39). 
Em 1928, o Decreto no 18.074 promoveu a reorganização do CNT, pontuando novas funções decorrentes das reivindicações trabalhistas, o que permitiu uma atuação mais próxima da jurídica. Organizou-se uma procuradoria, houve a fixação de regras procedimentais, além de se reconhecer formalmente a possibilidade do órgão aplicar multas e de intervenção mais incisiva nos conflitos trabalhistas (CABRAL, 2015, p.78-79). ${ }^{7}$

Assim, a ampliação das atribuições do CNT Ihe designou como competente, conforme expõe seu artigo 10 (BRASIL, 1928), para:

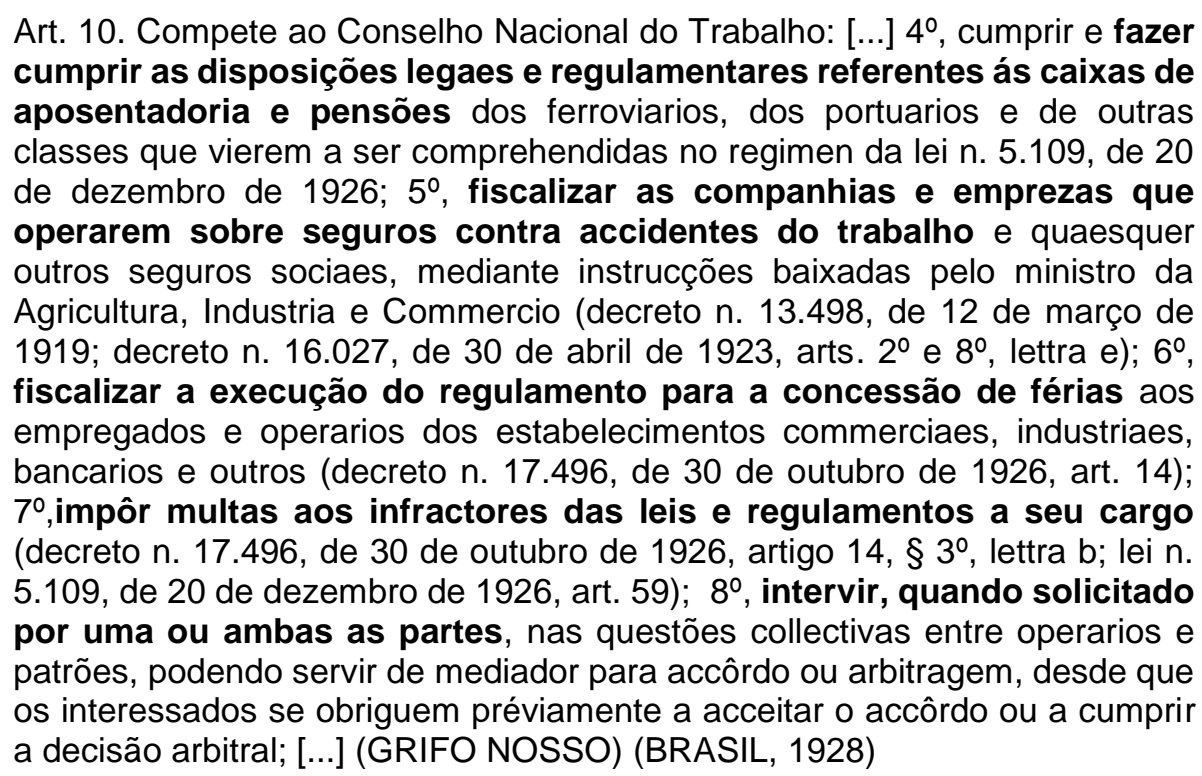

No que diz respeito aos descumprimentos à lei de férias, as limitações a sua aplicação e a sua posterior alteração merece uma atenção especial, sobremaneira

\footnotetext{
7 Em consulta às Revistas do CNT, um posicionamento importante da redação da revista, em resumo às observações do Presidente do CNT, e também desembargador do Tribunal de Justiça do Rio de Janeiro, Ataulpho de Paiva, encontrado em 1929, levava a uma nota pública de defesa da autonomia do conselho frente ao judiciário. Com o título $A$ situação do Conselho Nacional do Trabalho em face do Poder Judiciário, Paiva esclarecia que o CNT não se sobrepunha aos tribunais e que, como órgão da justiça social, tendo as suas atribuições ampliadas em lei, a tal ponto que se reveste do caráter de instância suprema em todas as questões que dizem com os interesses operários de que trata a sua constituição, o CNT "não deseja outra cousa que não seja fazer cumprir todas as decisões dos tribunaes, sem discutil-as, sejam ellas quaes forem. Isto não importa, porém, abrir mão das atribuições conferidas pela lei, porquanto, dentro della, o instituto será como tem sido inflexível.Se as partes entenderem, reluctando, apellar para o Judiciário, que o façam, sempre que lhes parecer aconselhável, que nem por isso o Conselho deixará de usar e manter integra a sua parcella de autoridade como peça já agora valiosa e importante do mecanismo da administração que é." (Revista CNT, 1929, p. 6).
} 
porque, em 1934, a revisão desta lei, criada dez anos antes, sofreu grande interferência da classe patronal.

O projeto de lei que iniciara com a proposta de férias para empregados da indústria e da lavoura chegou a sua versão final com aplicabilidade restrita aos empregados da indústria sindicalizados (SOUZA, 2007, p.43-44). Outra questão interessante foi a criação do artigo 30 da lei, que instituía a estabilidade por um ano dos empregados que propusessem reclamações em virtude desta lei, o que se tornava necessário diante das demissões frequentes dos funcionários que reclamavam o seu cumprimento (SOUZA, 2007, p.48-49).

No entanto, no que tange à atuação do CNT como árbitro, prevista no decreto que reestruturou o órgão, o sistema de arbitragem não parece ter sido concretizado, apesar de representar uma importante tentativa de fornecer uma resolução mais efetiva aos problemas trabalhistas, segundo Souza (2007, p.41).

Em 1931, o CNT passou a integrar o Ministério do Trabalho, Indústria e Comércio, criado pelo Decreto no 19.433, passando, então, por novas reorganizações do quadro pessoal e administrativo (UNTURA NETO, 2013, p.38).

Merece destaque, nesse sentido, as reformas de 1934 e 1939, respectivamente por meio dos Decretos no 24.784 e 1.346, que aproximaram significativamente o CNT da função judicante. Por meio delas, foiinstituído o Conselho Pleno,funcionando como um tribunal de embargos ou tribunal arbitral, cuja atribuição era atuar quando houvesse falhado as vias de conciliação, como também fora instituído na ocasião as Câmaras, como órgãos julgadores de primeira e segunda instância (UNTURA NETO, 2013, p.39-43).

O crescimento de atribuições do CNT se justifica, porém, a partir de duas perspectivas: a primeira, em razão da intensificação das normas e dos conflitos decorrentes das complexas particularidades das relações de trabalho, as quais estão atreladas o constante surgimento de novas necessidades decorrentes da dinâmica que orienta as relações de mercado. Mas havia também um aspecto político importante na centralização da resolução dos conflitos do trabalho no CNT, já que havia um interesse do Executivo de que tais conflitos não se convertessem em empecilho para o processo de industrialização iniciado no país. Segundo Marcos Untura Neto: 


\begin{abstract}
Concentrar a decisão dos conflitos trabalhistas no Poder Executivo foi uma decisão natural da política varguista sobre as relações de trabalho. Tratavase de centralizar a contenção de toda e qualquer possibilidade de conflito que pudesse impedir ou prejudicar o processo de industrialização em curso, imunizando o sistema da política regional. Assim, nos anos 1930 o rol de atribuições e competências do CNT foi largamente ampliado, de modo a atender a esse desígnio. (UNTURA NETO, 2013, p.49).
\end{abstract}

A seguir, passa-se ao registro das transformações do CNT até se concretizar em TST.

\title{
4 A FUNÇÃO JUDICANTE DO CONSELHO NACIONAL DO TRABALHO E A SUA TRANSFORMAÇÃO EM TRIBUNAL SUPERIOR DO TRABALHO
}

O CNT teve sua atribuição propriamente aproximada da resolução de conflitos a partir de 1932. Respectivamente a partir dos Decretos no 21.396 e ํㅡ 22.132, os embates entre trabalhadores e patrões ganharam possibilidade de resolução, através das Comissões Mistas de Conciliação (CMC) e das Juntas de Conciliação e Julgamento (JCJ). À primeira era incumbido o papel de "dirimir os dissídios entre empregadores e empregados", sendo constituída por vogais eleitos por ambas as classes (BRASIL, 1932).

As Juntas de Conciliação, por outro lado, seriam responsáveis por dirimir "litígios oriundos de questões de trabalho, em que sejam partes empregados sindicalizados, e que não afetem à coletividade a que pertencerem os litigantes" (BRASIL, 1932).

Segundo Samuel Fernando de Souza (2007, p.55), a existência de duas instituições com finalidades análogas era comum na época. Os dissídios individuais seriam os conflitos que envolviam, na sua maioria, "direitos reais", estabelecidos na legislação e os de caráter coletivo, pelo contrário, estavam no âmbito do conflito de classe, no qual a decisão final afeta toda a categoria. Dessa maneira,

De acordo com os critérios aceitos internacionalmente para constituição das cortes do trabalho, as JCJ seriam as instituições jurídicas por excelência, dado que ao lidarem com questões de "direito legal" teriam a prerrogativa de expedir sentença. Da mesma maneira, ocorria com o CNT nos anos 1920 ao tratar da dispensa de empregados estáveis, direito a pensões e férias. As 


\begin{abstract}
CMC eram muito parecidas com as cortes internacionais de arbitragem. [...]. A arbitragem das questões levadas às CMCs ocorreria apenas se as partes envolvidas no litígio não chegassem a nenhum acordo, caso falhasse o recurso da conciliação e aceitassem submeter a questão à decisão arbitral. Logo, a arbitragem facultativa implicava na difícil aceitação, por patrões e empregados, de que um grupo alheio aos seus interesses decidisse a respeito de seus litígios. A conciliação, expressa na lei que criou as Comissões, seria o melhor meio para o funcionamento das CMC dada a dificuldade de submissão da disputa à resolução arbitral (SOUZA, 2007, p.56).
\end{abstract}

As $\mathrm{JCJ}$ eram orientadas no sentido de fornecer uma justiça rápida, eficaz e acessível, sendo, por esse motivo, guiada pelos princípios de oralidade e informalidade, o que facilitava o acesso ao trabalhador (SOUZA, 2007, p.59-60). autor ainda assevera, todavia, que com relação ao julgamento de conflitos individuais, em sua maioria, a dificuldade residia em assegurar a aplicação prática do resultado alcançado na solução do litígio.

As sentenças expedidas quando não aceitas por uma das partes teriam de ser executadas pela Justiça Comum, o que se configurava como um substancial obstáculo à "justiça do trabalho", e findava por desencorajaros interessados na solução de conflitos a buscar tal meio de resolução de demandas (SOUZA, 2007, p.58).

Quanto às CMCs, muito se questionava em relação ao caráter de conciliação obrigatória e arbitragem facultativa como forma de "impedir a correta aplicação da lei" (SOUZA, 2007, p.61). A opção conciliatória era vista como uma maneira de fazer com que o empresariado apoiasse e respeitasse a ideia de regulamentação e regulação estatal. Tal instituto, inclusive, ainda éum recurso muito utilizado pela Justiça do Trabalho nos dias atuais, embora ainda se identifiquem fragilidades do seu alcance, especialmente diante das dificuldades de execução das garantias objeto da autocomposição.

Nas JCJs, detidamente, apesar de conservar o poder de impor sentenças, os acordos eram estabelecidos como prioridades, em face de pressupor uma maior predisposição para o cumprimento do avençado, o que tornava mais eficiente a atuação do CNT. Tal perspectiva era reforçada pelas dificuldades de execução dos julgamentos via sentença, como já exposto(SOUZA, 2007, p.198-202). Porém,a 
aplicação da lei estava ligada ao bom funcionamento destes dois diferentes mecanismos (JCJs e CMCs), que se comunicavam inevitavelmente.

Para além dos mecanismos judiciais, o serviço de fiscalização do CNT desempenhou um significativo papel na construção da Justiça do Trabalho, principalmente, se considerarmos a grande resistência à aplicação das leis do trabalho. Nesse sentido, salientava o importante papel destinado ao órgão o funcionário do Ministério do Trabalho Jacy Magalhães, ao relatar o papel e a atuação do serviço de fiscalização:

\begin{abstract}
A função de um fiscal, narra Jacy Magalhães, ele próprio elemento da fiscalização, era fundamental. Cabia a ele assegurar o cumprimento da legislação, enfrentando uma reação patronal que no começo foi de fato muito grande. O fiscal tinha amplos poderes punitivos; podia multar os empregadores e investigar as condições de trabalho nas empresas. Mas, fazendo isto, podia "convencer" (mesmo que através da "chantagem fiscal") o empregador dos benefícios da aplicação das leis e mostrar aos trabalhadores que o novo ministério queria lhes dar pleno apoio, desde que dentro das normas estabelecidas pela lei de sindicalização (SOUZA, 2007, p.108).
\end{abstract}

Após a vinculação do CNT ao recém criado Ministério do Trabalho, Indústria e Comércio, as inspetorias regionais do CNT cresceram em representatividade nas principais capitais do país. Muitos conflitos passaram a ser arbitrados diretamente pelos fiscais e inspetores do CNT nos Estados, ao mesmo tempo em que o aumento de reclamações trabalhistas se avolumou.

Em 1932, porém, na Bahia, a inspetoria teve a sua credibilidade abalada em virtude de acusações de fraudes nas fiscalizações, por parte de classes interessadas em fragilizar o CNT. Em contraposição, a declaração de Túlio Lima, responsável do Ministério do Trabalho, na avaliação da veracidade daquelas denúncias assevera a importante resistência dos inspetoresa serviço da fiscalização do CNT:

Não farei favores porque ninguém quer nem precisa de favores; farei sim com que se cumpra a lei. A legislação do trabalho, não favorece, como dizem somente aos trabalhadores, ela garante os direitos de ambos os lados. Se ao operário assiste razões, ela os garantirá; se, porém, o contrário se dá, também ela porá a salvo os direitos contrários. Nada de proteções nem favores, tudo pela lei, e dentro da lei (SOUZA, 2007, p. 107). 
Conflitos entre trabalhadores, empregadores e as inspetorias regionais do Trabalho, vinculadas ao CNT, eram comuns, como se pode notar no episódio ocorrido em Porto Alegre, no Rio Grande do Sul, na inspetoria chefiada pelo inspetor Ernani de Oliveira, em 1932-33. O conflito chegou a uma situação tão complexa que teve atuação direta do gaúcho e Ministro do Trabalho, Salgado Filho. ${ }^{8}$

Há diversos casos relatados nos processos do CNT que se referem a tentativas, pelos patrões, de burlar a aplicação da lei, inclusive sob orientação dos sindicatos patronais. Um exemplo é a lei que regulava o trabalho noturno das mulheres, prevendo que não poderia ultrapassar as 22:00 horas, exceto se o trabalho fosse em estabelecimento da família ou nos casos em que desempenhavam cargo de direção. Diante disso, os patrões criavam contratos de gerência para que mulheres que desempenhavam 0 trabalho de garçonete trabalhassem além do horário estabelecido pelo empregador, burlando a legislação relativa à jornada noturna feminina (SOUZA, 2007, p.130-136).

Embora se reconhecesse a importância do serviço de fiscalização do CNT, já que ele tinha poderes punitivos, possibilitando que os fiscais investigassem as condições de trabalho e multassem os empregadores pelo descumprimento da lei, reconhece-se que ele não está a salvo do jogo político, rede de amizades e favores pessoais notadamente diante do poderio econômico de muitos detentores de meios de produção (SOUZA, 2007, p.139-142). No entanto, essa função punitiva característica do CNT assumiu-se como figura importante por aproximar as atividades sindicais do Ministério do Trabalho, já que ambos eram entendidos como instrumentos em defesa dos direitos dos trabalhadores:

De qualquer maneira, as entidades sindicais que adotaram a estratégia de aproximação com a política oficial garantiram a manutenção de um espaço de luta que, embora limitado, possibilitava um estreito caminho para ver contempladas algumas medidas favoráveis aos trabalhadores. A articulação em torno da judicialização das relações de trabalho instaurava-se como arena imprescindível, tanto para as organizações sindicais, quanto para trabalhadores que, "individualmente" organizavam-se por melhores condições de trabalho. (SOUZA, 2007, p.144) ${ }^{9}$

\footnotetext{
${ }^{8}$ Para maiores detalhes, ver Cabral (2016).

${ }^{9}$ Ver ainda: Miranda (2017).
} 
Essas instituições criadas e aprimoradas durante a década de 1930, que funcionavam minimamente como uma forma possível de distribuição de justiça, conceberam os pressupostos para o surgimento da Justiça do Trabalho como um órgão efetivamente jurídico.

Esses institutos permitiram a aproximação com as realidades dos trabalhadores, e forneceram grande apanhado jurisprudencial inicialmente, além de um número significativo de especialistas no Direito do Trabalho (SOUZA, 2007, p.215220).

As demandas que o CNT enfrentou, pois, foram importantes subsídios para moldar uma Justiça especializada nos conflitos trabalhistas mais eficiente, baseada em princípios capazes de atender melhor aos anseios e às necessidades dos trabalhadores, tais como o princípio da oralidade, da conciliação e da proteção ao trabalhador hipossuficiente.

No entanto, o CNT também foi utilizado para atender às demandas ideológicas do Estado Nacional proposto por Getúlio Vargas. Essa constatação se torna clara quando se analisa os processos inventariados no fundo de arquivo do CNT, hospedado no TST, em Brasília. Dos mais de 50 mil acórdãos produzidos pelo CNT entre 1923 e 1945, apenas 973 processos foram preservados na íntegra. Se pudéssemos - para fins didáticos - organizar a Era Vargas em três momentos distintos: 1930 a 1934, como período do Governo Provisório; de 1934 a 1937, como período do Estado Constitucional e 1937 a 1945, como Estado Novo, é possível afirmar, a partir de uma acurada análise dos documentos do acervo pesquisado, que o CNT desenvolveu papéis distintos na proteção do trabalhador.

Como já observado nesta pesquisa, a característica judicante do CNT ocorreu com a reforma institucional de 1928, e na transição pós-Revolução de 1930, o conselho tornou-se protagonista para arbitrar conflitos e fiscalizar o cumprimento da legislação laboral, principalmente após a reforma de julho de 1934, dias antes da promulgação da Constituição de 1934. Contudo, o contexto conturbado que marcou os primeiros meses de 1935, até mesmo com a criação da Lei n. 38 - Lei de Segurança Nacional, de 04 de abril de 1935, que reorganizou o rol dos crimes contra a ordem social para incluir ações de movimentos sociais e de trabalhadores consideradas de ódio ou de violência entre as classes sociais ou ainda de paralisação 
de serviços públicos ou de abastecimento da população, a função do CNT tornou-se mais política do que jurídica.

Com o aumento significativo das greves houveram inúmeros pedidos de empregadores ao CNT para homologarem os inquéritos administrativos para apurar faltas graves, realizados pelas empresas, contra os líderes grevistas. O estopim desse movimento se concretizou com as greves em decorrência da intentona comunista, em novembro de 1935, que permitiu ao próprio Ministro do Trabalho atuar em sede recursal para reverter as decisões colegiadas dos conselheiros do CNT e autorizar a demissão de grevistas.

Os processos em análise (com destaque aos de 1935-1937) demonstraram como a ideologia que determinou os sentidos da greve como uma ação antissocial ao trabalho e ao capital se concretizou em uma perseguição ao direito de greve já em 1935, e sua posterior criminalização a partir da Constituição de 1937.

A ideologia trabalhista que marcou o período produziu uma narrativa importante (que remonta às experiências sobre trabalhadores desde a Primeira República) sobre a característica dos trabalhadores brasileiros, considerados ordeiros e de boa convivência com os patrões, ao mesmo tempo em que caracteriza como indesejáveis os trabalhadores desordeiros, vinculados aos movimentos de trabalhadores comunistas, socialistas e combativos (GOMES, 2005; MENEZES, 1996).

Essas transformações se direcionaram à forma como os órgãos da Justiça do Trabalho deveriam ocorrer para dar respostas aos novos tempos. Foi na última reforma do CNT, em 1939, que a organização da Justiça do Trabalho propriamente dita somente surgiu, com os Decretos-lei o 1.237 e 1.346, prevendo o CNT como "tribunal superior da Justiça do Trabalho" (BRASIL, 1939).

No entanto, apenas em 1941 a Justiça do Trabalho foi inaugurada. A sua organização contava com as JCJs na base, mantendo as suas principais características, exceto no que tange à presidência da junta, que passou a ser composta por um juiz de direito ou bacharel escolhido para um mandato de dois anos. Contava, ainda, com os Conselhos Regionais do Trabalho, em nível intermediário, bem como como CNT, atuando como instância superior (MOREL e PESSANHA, 2007, p.90). 
A transformação do CNT em Tribunal Superior do Trabalho, no entanto, ocorreu por meio do Decreto-lei no 9.797, em 1946, o integrando ainda ao Poder Executivo. A Justiça do Trabalho só passou efetivamente a compor o âmbito do judiciário posteriormente, com a promulgação da Constituição de 1946.

\section{CONCLUSÃO}

Tendo em vista o contexto socioeconômico vigente até 1917, o início do debate político e as tímidas legislações trabalhistas e previdenciárias existentes, o processo de instituição de um órgão como o CNT significou, à primeira vista, um importante passo no sentido de encarar as mudanças ocorridas na realidade do trabalho no país, durante a transição de uma economia baseada no setor primário para uma economia industrializada. Todavia, para além disso, a instituição do CNT inaugurou uma forma de visualizar e dar efetividade aos "novos direitos", potencializando a possibilidade dos trabalhadores efetivamente usufruí-los.

A ampliação de funções do CNT no decorrer das décadas de 1920 e 1930, mostra, com clareza, a percepção que os trabalhadores tinham sobre o órgão como uma entidade de caráter não meramente consultivo, mas como uma instituição a qual poderiam recorrer a fim de garantir a implementação de seus direitos recém instituídos.

Os pedidos, nesse período, ainda eram acanhados, sem os discursos jurídicos que permeiam os processos e tinham um teor muito mais de apelação, como se o CNT fosse um órgão de efetiva proteção do trabalhador.

A evolução do CNT ocorrida a partir do alargamento das suas atribuições the conferiu a função de processar, julgar e executar as reclamações trabalhistas, o que acarretou numa maior necessidade de aproximação da perspectiva jurídica.

Foram instituídos procedimentos, institutos, fontes e formas de argumentação, os quais foram essenciais para a compreensão que se tem hodiernamente da Justiça do Trabalho como uma instituição que também assume poderes normativos; como órgão que dá voz a direitos sociais, de modo a fornecer maior proteção ao trabalhador, visando contribuir para a realização do princípio da equidade. As crescentes 
demandas sociais e jurídicas dirigidas ao CNT, pois, foram elementares para o Estado brasileiro perceber a importância de uma justiça especializada na resolução de conflitos do trabalho.

Por fim, é preciso enfatizar que a instituição do CNT favoreceu os diálogos entre patrão, trabalhador e Estado, principalmente, por meio das CMCs e JCJs, proporcionando o fortalecimento da legislação trabalhista e favorecendo a sua aplicação, ainda que diante de contextos de muita contraposição e resistência.

Para os trabalhadores, a possibilidade de ver seus direitos atendidos fomentou a apropriação de um discurso jurídico e a criação de uma "consciência legal", que até podia não ser um conhecimento técnico substancial dos procedimentos, mas a mera noção em relação à existência dos direitos, o que já é um elemento importante para a garantia das prerrogativas laborais.

Como afirma Souza (2007, p.220), independente de conhecimento ou assistência jurídica, muitos trabalhadores passam a visualizar essa instância jurídica como uma "arena de lutas". Ademais, assinala Silva (2012, p.160), que essas instituições eram uma possibilidade de conquista de direitos não somente porque "os de baixo" se aproximaram das funções do Estado e tomaram acessaram a espaços que antes não ocupavam, mas porque do CNT não exalava apenas o formalismo retórico, o desejo de imobilismo e a improvisação irresponsável que muitas vezes orientam a atuação dos órgãos e instituições do poder público.

\section{REFERÊNCIAS}

BARBOSA, Pedro Paulo Lima. Legislação Social e Trabalhista no Brasil: vertentes historiográficas. In: IV Congresso Internacional de História. Maringá, 2009.

BIAVASCHI, Magda Barros. Direito e Justiça do Trabalho no Brasil: Notas sobre uma trajetória com bem mais de 70 anos. Revista TST, Brasília, v. 77, n. 2, p.83-102, abr./jun. 2011.

BRASIL. Constituição (1934). Constituição da República dos Estados Unidos do Brasil. Diário Oficial da União, 16 jul. 1934. Disponível em: <http://www.planalto.gov.br/ccivil_03/constituicao/constituica034.htm> Acesso em 01 de ago. 2017 
. Decreto no 1.237, de 02 de maio de 1939. Organiza a Justiça do Trabalho. Diário Oficial da União, 02 mai. 1939.

Decreto no 16.027, de 30 de abril de 1923. Cria o Conselho Nacional do Trabalho. Diário Oficial da União, 10 mai. 1923.

Decreto no 21.396, de 12 de maio de 1932. Institui Comissões Mistas de Conciliação e dá outra providencias. Diário Oficial da União, 16 mai. 1932.

Decreto no 22.132, de 25 de novembro de 1932. Institui Juntas de Conciliação e Julgamento e regulamenta as suas funções. Diário Oficial da União, 25 nov. 1932. $\overline{(1923-1945) .}$

TST. Tribunal Superior do Trabalho. Fundo Conselho Nacional do Trabalho

CABRAL, Rafael Lamera. Da resistência ao ajuste: o trabalhador na década de 1930. Revista Direito e Práxis, Rio de Janeiro, 2017. Disponível em: http://www.epublicacoes.uerj.br/index.php/revistaceaju/article/view/26411/21426. Acesso em: 01.out. 2017.

Nos rastros de um processo: Direitos sociais e a atuação do Conselho Nacional do Trabalho (1934-1938). Texto de Qualificação de Tese de Doutorado. Brasília, 2015. [Mensagem pessoal]. E-mail recebido por rafaelcabral@ufersa.edu.br em 02 Jul. 2017.

. Nos rastros de um processo: trabalho, conflito e uma experiência de micro-história. 422 f. Tese (Doutorado) - Programa de Pós-Graduação em Direito, Universidade de Brasília, Brasília, 2016.

FAUSTO, Boris (Org). História Geral da Civilização Brasileira. Tomo III. O Brasil republicano. 8. ed. Rio de Janeiro: Bertrand Brasil, 2006.

FAUSTO, Boris. História do Brasil. 2. ed. São Paulo: Editora da Universidade de São Paulo: Fundação do Desenvolvimento da Educação, 1995.

GOMES, Angela Maria de Castro. A invenção do trabalhismo. $3^{a}$ ed. Rio de Janeiro: Editora FGV, 2005.

. Burguesia e trabalho: política e legislação social no Brasil 1917-1937. Rio de Janeiro: Campus, 1979.

GOMES, Angela de Castro; SILVA, Fernando Teixeira da (Orgs.). A Justiça do Trabalho e sua história: os direitos dos trabalhadores no Brasil. Campinas: Editora da Unicamp, 2013.

GUERRA, Maria Pia. Anarquistas, trabalhadores, estrangeiros: 0 constitucionalismo brasileiro na primeira República. Curitiba: Prismas, 2015. 
MIRANDA, Daniel Estevão Ramos de. Do Direito do Trabalho à judicialização das relações sociais: notas sobre Werneck Vianna. Revista Jurídica da Universidade Federal Rural do Semi-árido, Mossoró-RN, vol. 1, n. 1, p. 71-88, 2017.

MENEZES, Lená Medeiros de. Os indesejáveis: desclassificados da modernidade. Protesto, crime e expulsão na Capital Federal (1890-1930). Rio de Janeiro: EdUERJ, 1996.

MOREL, Regina Lúcia M.; PESSANHA, Elina G. da Fonte. A justiça do Trabalho. Tempo social, revista de sociologia da USP, São Paulo, v. 19, n. 2, p. 87-109, nov. 2007.

OLIVEIRA, Moacyr Velloso Cardoso de. Um pouco de história da previdência social - Conselho Nacional do Trabalho, suas origens. Revista de Previdência Social, Brasília, v. 12, n. 90, p. 269-271, mai.1988.

SOUZA, Samuel Fernando. Coagidos ou Subornados: trabalhadores, sindicatos, Estado e leis do trabalho nos anos de 1930. 2007. 228p. Tese (Doutorado) Universidade Estadual de Campinas, Instituto de Filosofia e Ciências Humanas. Campinas, 2007.

SILVA, Fernando Teixeira da. "Justiça de Classe": tribunais, trabalhadores rurais e memória. Revista Mundos do Trabalho, v.4, n. 8, p. 124-160, jul./dez. 2012.

UNTURA NETO, M. O Conselho Nacional do Trabalho e a construção dos direitos sociais no Brasil. 2013. 190 f. Dissertação (Mestrado) - Faculdade de Direito da Universidade de São Paulo. São Paulo, 2013. 